Original Article

\title{
KNOWLEDGE, ATTITUDE AND PRACTICE REGARDING HOSPITAL DELIVERY AMONG RURAL MARRIED WOMEN IN NORTHERN BANGLADESH
}

\author{
Nawzia Yasmin, Khairul Alam, Suman Lahiry, Mahmud Hossain Faruquee, Tamjida Ahmad \\ Department of Public Health, State University of Bangladesh
}

\begin{abstract}
Various programs for safe motherhood aiming to reduce maternal and neonatal mortality are undertaken by public sectors as well as the NGOs. This descriptive cross-sectional study was conducted on the married women in their reproductive age (15-40y) belonging to 211 households of Shitlai village of Kahalu Thana of Bogra district in Bangladesh from January to April 2007. Using a semi-structured questionnaire, data were collected by door-to-door visits and through face-to-face interviews with the respondents. Considering the knowledge on safe motherhood and safe delivery, majority of the respondents $(98.6 \%)$ mentioned that every pregnant mother should receive antenatal care, and $97.6 \%$ said that pregnancy is a period of risk. Regarding safety, $96.2 \%$ mentioned hospital delivery as safe, while $80.6 \%$ mentioned home delivery as a risk. Among the respondents, $70.1 \%$ said that ANC is important, $29.9 \%$ was found to be informed of child birth complications, $16.1 \%$ knew the duration of pregnancy, $8.1 \%$ knew the danger signs of pregnancy, $4.7 \%$ about emergency obstetric care (EOC), $4.3 \%$ about expected date of delivery (EDD), $2.4 \%$ about safe motherhood and $28.4 \%$ about the access of health facilities in the village. Among the respondents, $85.3 \%$ showed a positive attitude towards hospital delivery while $14.7 \%$ had a negative attitude. Study also showed that majority of the respondents (66.8\%) had delivered at home, and only onefourth of the respondents delivered their index child in a hospital. Thus the study recommends to improve the knowledge, economic status, to change the decision making process through the launching of different activities with appropriate health programmes.
\end{abstract}

Ibrahim Med. Coll. J. 2009; 3(1): 17-20

Key Words: Knowledge, attitude and practice (KAP), hospital delivery, married women

\section{Introduction}

Pregnancy and childbirth related complications are among the leading causes of maternal mortality in Bangladesh. Lack of knowledge about ANC and place of delivery is responsible for such a situation. According to Bangladesh Demographic and Health Survey Report (2004), only $13 \%$ of births in Bangladesh are assisted by doctors, trained nurses and midwives. ${ }^{1}$ The utilization of safe motherhood services including maternity care in Bangladesh is very poor. If the respondents suffer from diseases/symptoms, then it is more likely that the delivery would take place at the mother's home. ${ }^{2}$
Study conducted on prevalence of home deliveries and antenatal care coverage in some selected villages found that $83 \%$ of the respondents received antenatal checkup throughout their last pregnancy. ${ }^{3}$ There was association between the place of delivery and level of education and family income of the respondents. Also there were associations of utilization of antenatal care with level of education and family income of the respondents. ${ }^{3}$

Core components of maternal and child health, like safe delivery and safe motherhood, have been focused

Address for Correspondence:

Nawzia Yasmin, Head and Academic Program Director, Department of Public Health, State University of Bangladesh 
in the MDGs and HNPSP. The peripheral and hard to reach areas show crux of the menace regarding such issues and are areas of priority for research. Owing to socio-demographic, socioeconomic, socio-cultural as well as knowledge, attitude, belief and practice related factors, hospital delivery among rural married women are still poor. There is lack of such studies in this field and in the study area of Bogra, no such study could be found. Therefore, it was attempted to explore the knowledge, attitude and practice regarding hospital delivery among rural women in Bangladesh.

\section{Methodology}

The present descriptive cross-sectional study was done on the married women of reproductive age (15-40y) of 211 households of Shitlai village of Kahalu Thana of Bogra district in Bangladesh from January to April, 2007. Using a semi-structured questionnaire, data were collected by door-to-door visits and through a face-toface interview with the respondents.

\section{Results}

A factorial analysis of principal component analysis (PCA) to assess the composite knowledge of duration of pregnancy, expected date of delivery, emergency obstetric care, availability and receiving of ANC in the village, pregnancy as a period of risk, vaccination during pregnancy, danger sings during pregnancy, home delivery as risk were done. It was found that, about one-third $(34 \%)$ of the respondents had a poor knowledge, $40 \%$ had average and $25.6 \%$ had good knowledge (Table-1).

Table-1. Distribution of the respondents by level of attitude on safe motherhood $(n=211)$

\begin{tabular}{lrr}
\hline Variables & No. & \multicolumn{1}{c}{$\%$} \\
\hline Importance of ANC for every mother & 211 & 100.0 \\
Attitude for hospital delivery & 211 & 100.0 \\
Attitude to seek care during danger signs & 210 & 99.5 \\
Attitude towards vaccination & & \\
$\quad$ during pregnancy & 209 & 99.1 \\
Motivate others for hospital delivery & 208 & 98.6 \\
Married women having & & \\
$\quad$ knowledge on danger signs & 207 & 98.1 \\
Male attendance during labour & 84 & 39.8 \\
Autonomy in treatment seeking & 12 & 5.7 \\
Hospital delivery considered as shameful & 11 & 5.2 \\
Hospital delivery considered as sin & 2 & 0.9 \\
Obstacle from family & 1 & 0.5 \\
\hline
\end{tabular}

Table-2. Distribution of the respondents by level of practice on safe motherhood

\begin{tabular}{|c|c|c|}
\hline Variables & Frequency(n) & Percentage(\%) \\
\hline \multicolumn{3}{|c|}{ Registered for health problem } \\
\hline Yes & 203 & 96.2 \\
\hline No & 8 & 3.8 \\
\hline \multicolumn{3}{|c|}{ Taking suggestions from hospital } \\
\hline Yes & 11 & 5.2 \\
\hline No & 200 & 94.8 \\
\hline \multicolumn{3}{|c|}{ Faced complications at home during delivery } \\
\hline Yes & 30 & 14.2 \\
\hline No & 164 & 77.7 \\
\hline Not applicable & 17 & 8.1 \\
\hline \multicolumn{3}{|c|}{ Trained Birth Attendant at delivery } \\
\hline Yes & 11 & 5.2 \\
\hline No & 18 & 8.5 \\
\hline Not applicable & 182 & 86.3 \\
\hline \multicolumn{3}{|c|}{ Ever practiced ANC } \\
\hline Yes & 152 & 72.0 \\
\hline No & 43 & 20.4 \\
\hline Not applicable & 16 & 7.6 \\
\hline \multicolumn{3}{|c|}{ Vaccination during last pregnancy } \\
\hline Yes & 150 & 71.1 \\
\hline No & 45 & 21.3 \\
\hline Not applicable & 16 & 7.6 \\
\hline \multicolumn{3}{|c|}{ Index birth at hospital } \\
\hline Yes & 53 & 25.1 \\
\hline No & 140 & 66.4 \\
\hline Not applicable & 18 & 8.5 \\
\hline \multicolumn{3}{|c|}{ History of hospital delivery } \\
\hline Yes & 52 & 24.6 \\
\hline No & 141 & 66.8 \\
\hline Not applicable & 18 & 8.5 \\
\hline \multicolumn{3}{|c|}{ Any family member had practice of hospital delivery } \\
\hline Yes & 113 & 53.6 \\
\hline No & 98 & 46.4 \\
\hline
\end{tabular}

Based on principal component analysis (PCS) among the interviewed respondents, $85 \%$ had a positive attitude towards hospital delivery and the rest showed a negative attitude towards hospital delivery.

Regarding the level of attitude on safe motherhood on different aspects, it was found that, all the respondents had a positive attitude towards importance of ANC and hospital delivery, seeking care after notification of danger sign and vaccination. However, $40 \%$ of the respondents did not agree to the presence of male attendants during labor. Most striking finding was that, only $6 \%$ had autonomy in health care seeking behavior. Very few opined that hospital delivery is a sin or shameful practice. 
Regarding the practice of safe motherhood, it was found that $96 \%$ of the respondents registered for their health problems. However, few of them took suggestions from a hospital. Among the interviewed respondents, 14\% faced complications at home during last pregnancy. It was found that $72 \%$ received $\mathrm{ANC}$ and an equal percentage received TT vaccine during last pregnancy. One-fourth of the respondents delivered their index child in the hospital.

Majority of the respondents $(79.6 \%)$ had knowledge on the place of safe delivery, $49.3 \%$ respondents gave their opinion on hospital delivery as safe. Regarding the necessity of Caesarean section during labour, 98.6\% respondents were not in favour. Almost half (48.8\%) of the respondents preferred TBA as a birth attendant. Regarding access to health care facilities, $16.1 \%$ and $35.5 \%$ of the respondents did not know the availability of TBA and MCH clinic in the village respectively. A fourth $(24 \%)$ of the respondents gave history of birth complications with prolonged labour being the major $(44.2 \%)$ cause. It was found that $34.1 \%$ of the respondents had a poor knowledge on safe motherhood and only $25.6 \%$ had a good knowledge. Majority had poor knowledge on pregnancy and childbirth related complications. Regarding attitude on safe motherhood, it was found that only $6 \%$ had autonomy in health care seeking behavior. Over all, $85.3 \%$ were positive towards hospital deliveries. It was found that only $25.1 \%$ of the respondents had their index birth in a hospital, $66.8 \%$ never went for hospital delivery and $53.6 \%$ reportedly mentioned that some of their family members had a hospital delivery.

\section{Discussion}

In a study on complications of pregnancy in rural Bangladesh, it was stated that more than half of the women in Abhoynagar and $40 \%$ women in Mirsarai were aware of the availability of trained TBAs in their community. The study further showed that $83 \%$ of the respondents received antenatal check-ups throughout their last pregnancy. Out of 505 respondents $91.3 \%$ of the respondents were found to have delivered at home while only $8.7 \%$ had institutional deliveries. ${ }^{4}$

In a similar study on obstetric complications, health care seeking behavior and cost involved in it in rural Bangladesh, it was found that, among the respondents $74 \%$ had history of home delivery out of which only $26 \%$ was reported to deliver in the hospital. ${ }^{5}$ In another study in a village of Manikgonj District of Bangladesh, ${ }^{6}$ 8 out of 10 women had maternal health problems, while almost all deliveries $(97 \%)$ took place at home. In a study on mother and child health care in Kabul, Afghanistan ${ }^{7}$ with focus on the mother, it was found that sixty-one out of 100 women in the community, delivered at home exclusively, 35 having experienced both home and institutional deliveries, four women had hospital childbirths only. In a small Nigerian community, ${ }^{8}$ it was found that, although a functioning government maternity center in the community offered a full range of antenatal and delivery services, most of the women did not register for ANC until their sixth month of pregnancy or later, and $65 \%$ delivered at home. All these reviews suggest that the findings on rural deliveries in the developing countries are almost similar in nature and the present findings of this study are no different.

\section{Conclusion}

Addressing the special needs of the pregnant mother, $\mathrm{MCH}$ program should be designed and different IEC and BCC programs should be launched to increase the knowledge about childbirth complications, EOC, ANC/ $\mathrm{PNC}$, and practice of hospital delivery. Home delivery should be discouraged and institutional/hospital delivery should be encouraged. Steps should be taken for utilizing the existing EOC and $\mathrm{MCH}$ facilities properly.

\section{References}

1. Bangladesh Demographic and Health Survey Report 2004.

2. Islam MA, Chowdhury RI, Akhter HH. Complications during pregnancy, delivery, and postnatal stages and place of delivery in rural Bangladesh. Health Care Women Int 2006; 27(9): 807-21.

3. Barbhuiya MA, Hossain S, Hakim MM, Rahman SM. Prevalence of home deliveries and antenatal care coverage in some selected villages. Bangladesh Med Res Counc Bull 2001; 27(1): 19-22.

4. Khanum PA, Quaiyum MA, Islam A. Complications of pregnancy and childbirth: knowledge and practices of women in rural Bangladesh Dhaka, Bangladesh, International Centre for Diarrhoeal Disease Research, Bangladesh [ICDDR,B], Centre for Health and Population Research, 2000. iv, 22 p. (ICDDR,B Working Paper No. 131). 
5. Khan AK. Obstetric complications: the health care seeking behavior \& cost pressure generated from it in rural Bangladesh. Mymensingh Med J 2002; 11(2): 110-2.

6. Bangladesh: 8 in 10 women have maternal health problems. Safe Mother 1995; (19): 3.

7. Kaartinen L, Diwan V. Mother and child health care in Kabul, Afghanistan with focus on the mother: women's own perspective. Acta Obstet Gynecol Scand 2002; 81(6): 491-501.

8. Brieger WR, Luchok KJ, Eng E, Earp JA. Use of maternity services by pregnant women in a small Nigerian community. Health Care Women Int 1994; 15(2): 101-10. 